\title{
Antibiotic Resistance of Typhoidal Salmonella Isolated from Humans in Kaduna and its Associated Factors
}

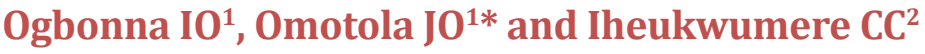

${ }^{1}$ Department of Microbiology, Federal University of Agriculture Makurdi, Nigeria

${ }^{2}$ Department of Botany, Federal University of Agriculture Makurdi, Nigeria

*Corresponding author: Justina Omotola, Department of Microbiology, Federal University of Agriculture Makurdi, Benue State, Nigeria, Tel: +2348101860672; Email: justinaomotola@ yahoo.com

\section{Research Article \\ Volume 6 Issue 1}

Received Date: December 07, 2020

Published Date: January 08, 2021

DOI: $10.23880 /$ oajmb-16000181

\section{Abstract}

Background: Pathogenic Salmonella species cause various types of infections ranging from mild gastroenteritis to lifethreatening typhoid fever caused by Salmonella typhi, or paratyphoid fever caused by S. paratyphi A, B or C; of which $S$. paratyphi A is prevalent. Currently, treatment of typhoid infection is being hampered by the emergence of multidrug-resistant strains, while vaccines provide only temporal or partial protection.

Objective: The aim of the study was to determine antibiotic resistance of typhoid causing Salmonella isolated from human stool.

Methodology: A cross-sectional descriptive study was carried out in the capital city of Kaduna State, Nigeria. Questionnaires were administered to 300 consenting individuals; comprising 250 patients and 50 volunteering healthy individuals, to obtain relevant socio demographic and clinical information. Stool specimens were equally collected in sampling containers for isolation of typhoidal Salmonella on Salmonella Shigella Agar. Suspected typhoidal Salmonella colonies were confirmed by biochemical tests as $S$. typhi or $S$. paratyphi A, before antimicrobial susceptibility test was done using Kirby-Bauer disk diffusion method. Diameters of zone of inhibitions were recorded and interpreted according to Clinical Laboratory Standards Institute guidelines. The data and results obtained were represented on tables and charts. Chi-square analysis was also used to determine statistical association among parameters and p-values $\leq 0.050$ were considered significant.

Results: Thirty-two (32) typhoidal Salmonella were isolated; 25 were S. typhi and seven S. paratyphi A. Thirty isolates came from patients while two were isolated among healthy individuals. High antibiotic resistance was observed with Augmentin (100\%), Ceftazidime (87.5\%), Cefuroxime (84.4\%), Cefixime (84.4\%) and Gentamicin (40.6\%), while Ciprofloxacin (12.5\%), Nitrofurantoin $(12.5 \%)$ and Oflaxacin (18.8\%) showed a lower resistance. Age, marital status and state of origin were socio demographic factors found to be associated with the antibiotic resistance. Also, frequency of infection, presenting symptoms and sampling duration were statistically associated with the antibiotic resistance.

Conclusion: Multi-drug resistance, high antibiotic resistance of typhoidal Salmonella and factors associated with it in this study, should awaken public health concerns in curbing the excesses of typhoidal Salmonella.

Keywords: Antibiotic Resistance; Typhoidal Salmonella; Isolates; Typhoid Infection 


\section{Open Access Journal of Microbiology \& Biotechnology}

Abbreviations: KIA: Kligler Iron Agar; MRVP: Methyl Red-Voges Proskauer; HMA: Mueller-Hinton Agar; NIT: Nitrofurantoin; GEN: Gentamicin; CXM: Cefixime; CPR: Ciprofloxacin; OFL: Ofloxacin; CAZ: Ceftazidime; AUG: Augmentin; CRX: Cefuroxime; SSA: Salmonella Shigella Agar; SPSS: Statistical Package for the Social Sciences; CLSI: Clinical Laboratory Standards Institute.

\section{Introduction}

In recent times, research on Salmonella has attracted the attention of clinical microbiologists, epidemiologists, geneticists and even molecular biologists [1]; more particularly because Salmonella typhi is host restricted to humans [2] and has the ability to bypass host immune defences [3]. Host restrictions to humans speculate that it might be transmitted by sex occasionally [4]. Salmonella enterica serovar Typhi otherwise known as Salmonella typhi, cause typhoid fever, while a similar paratyphoid fever is caused by S. enterica serotype Paratyphi A, B or C [5], of which Salmonella paratyphi A is most prevalent [6]. Although some Salmonella infections resolve without treatment, resistant infections like typhoid fever may not respond to first-line drugs, thus are commonly associated with longer illness and more severe outcomes [7]. Salmonella are Gram-negative bacteria which are particularly resistant to antibiotics because they possess two membranes that protect them from harmful substances [8]. Typhoid infections are becoming increasingly difficult to treat with antibiotics, forcing researchers to look for alternatives to control these pathogens [8]. Multiple drug resistance transmitted genetically by plasmids among enteric bacteria is also a key problem in treating typhoid infections [9].

Despite availability of more recent data on typhoid fevers, it remains a significant health burden [10]. Therefore, understanding antibiotic resistance in individuals, especially in areas where high antibiotic resistance strains are likely to hamper treatment [10], will aid an optimal and timely antimicrobial treatment of patients, which is also important for reducing the high infection and mortality rate associated with typhoid fevers in developing countries like Nigeria [11]. The present work determined the antibiotic resistance of typhoidal Salmonella isolated from stool of patients and healthy individuals in Kaduna.

\section{Methods}

\section{Study Area and Design}

This was a cross-sectional descriptive study carried out in the capital city of Kaduna State, Nigeria (Figure 1), between July 2018 and February 2019. Ethical approval/ clearance was obtained from the Ministry of Health and
Human resources and Barau Dikko Teaching Hospital Health Research and Ethical Committee in Kaduna State. Consent was duly sought and obtained from participants ( $>15$ years) enrolled into the study or from guardians (for participants $\leq$ 15 years).

\section{Study Population}

The study population comprised of 50 healthy volunteering individuals and 250 patients who visited any of four selected general hospitals in the metropolis; General Hospital Sabon Tasha, Gwamna Awan General Hospital Kakuri, Barau Dikko Teaching Hospital Ungwan-Rimi and Yusuf Dantosho Memorial Hospital Tudun Wada, with suspected cases of typhoid/paratyphoid fever by clinical diagnosis, within the study duration.

\section{Sample and Data Collection}

Stool specimens were obtained from participants in stool sampling bottles and immediately transported to the microbiology laboratory for isolation of Salmonella typhi or paratyphi A on Salmonella Shigella Agar (SSA), using standard bacteriological procedures. Well-structured questionnaires were also used to collect relevant socio-demographic data and clinical information.

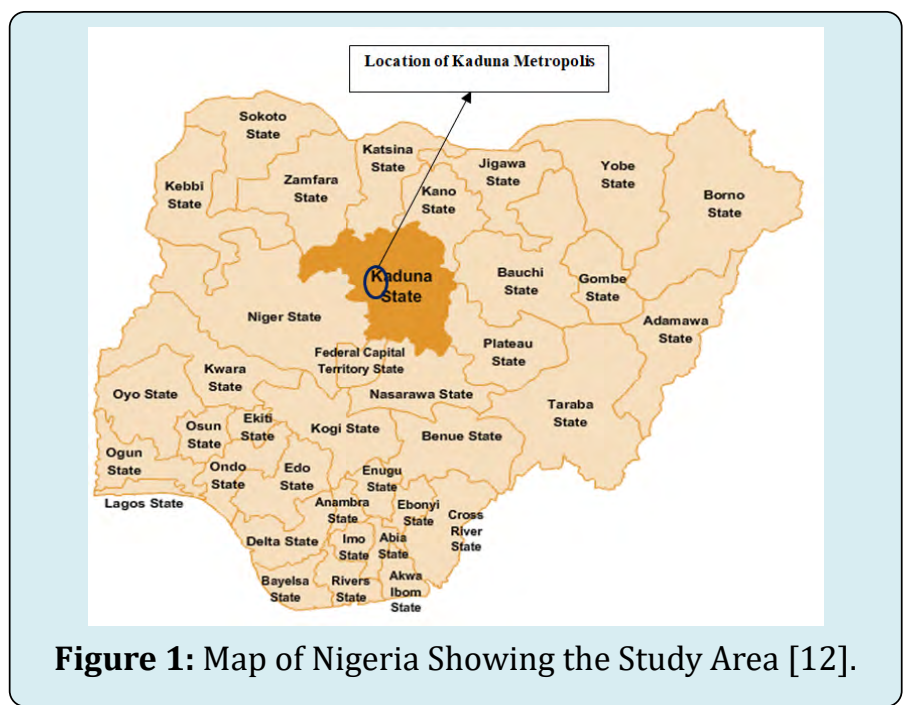

\section{Isolation of Typhoidal Salmonella}

A pinch of each stool sample was enriched in Selenite F broth (HIMEDIA Laboratories Ltd., India) and incubated at $37^{\circ} \mathrm{C}$ for $6-12$ hours, and using aseptic laboratory procedures, a loop full of the enriched broth was cultured by streaking onto prepared plates of SSA (Lab M Limited, Heywood Lancashire, United Kingdom). The plates were incubated aerobically at $37^{\circ} \mathrm{C}$ for $18-24$ hours, after which they were observed for characteristic culture/colony formations of 


\section{Open Access Journal of Microbiology \& Biotechnology}

typhoidal Salmonella; smooth, circular, convex, colourless, transparent, flat colonies with a clear or black centre $[13,14]$.

\section{Biochemical Confirmation of Typhoidal Salmonella}

Suspected colonies of typhoidal Salmonella on SSA were confirmed with biochemical tests on appropriate media and performed with standard operational procedures. The biochemical tests included; Kligler Iron Agar (KIA), urease (Titan Biotech Ltd., Rajasthan, India), motility, indole, Methyl Red - Voges Proskauer (MRVP), citrate utilization, lysine decarboxylase (HiMedia Laboratories Pvt. Ltd., India), Gram staining, catalase and oxidase tests.

\section{Antibiotic Susceptibility Test}

Confirmed Salmonella isolates were further subjected to antibiotic susceptibility test - Kirby-Bauer disk diffusion method, using a Gram negativedisk (Abtek Biologicals Limited, Liverpool, UK; sensitivity rings NZ53N), which contained the following antibiotics; Ceftazidime (CAZ) $(30 \mu \mathrm{g})$, Cefuroxime

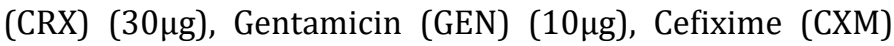

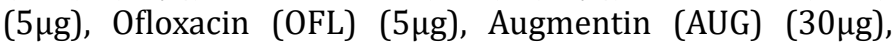

Nitrofurantoin (NIT) $(300 \mu \mathrm{g})$ and Ciprofloxacin (CPR) $(5 \mu \mathrm{g})$. The disk was placed firmly on Mueller-Hinton Agar (HMA) plates (TM MEDIA, Titan Biotech Limited, India), streaked with identified colonies of Salmonella typhi or paratyphi A. The plates were incubated at $37^{\circ} \mathrm{C}$ for 24 hours, after which diameters of zone of inhibitions were measured to the nearest millimeter with a transparent ruler and interpreted according to the guidelines of Clinical Laboratory Standards Institute (CLSI) [15].

\section{Analysis of Data}

Data generated both from laboratory experiments and questionnaires were presented as frequency tables and charts. Chi-square analysis was done on IBM SPSS version 20 and $p$-values $\leq 0.050$ at $95 \%$ confidence level was considered significant for parameters examined.

\section{Results}

Thirty-two (32) typhoidal Salmonella isolates were recorded; twenty-five (25) were S. typhi isolates and seven (7) were $S$. paratyphi A. Thirty (30) isolates came from patients while two (2) were isolated among healthy volunteering individuals as shown on Table 1.

\begin{tabular}{|c|c|c|c|c|c|c|}
\hline Category of Participants & HV & BD & GA & GS & YM & Total \\
\hline Number of participants & 50 & 50 & 93 & 57 & 50 & 300 \\
\hline No Typhoidal Salmonella Isolated & 48 & 44 & 80 & 51 & 45 & 268 \\
\hline S. typhi Isolated & 1 & 4 & 11 & 5 & 4 & 25 \\
\hline S. paratyhpi A Isolated & 1 & 2 & 2 & 1 & 1 & 7 \\
\hline Total Number of Isolates & 2 & 6 & 13 & 6 & 5 & 32 \\
\hline
\end{tabular}

Table 1: Distribution of Isolated Typhoidal Salmonella According to Categories of Participants.

Healthy Volunteers (HV), Barau Dikko Teaching Hospital (BD), Gwamna Awan General Hospital (GA), General Hospital Sabon Tasha (GS) and Yusuf Dantosho Memorial Hospital (YM).
Ages of participants ranged from a two-week old baby to a 72-year-old man. A frequency distribution of isolates by age grouping is shown on Table 2. Age group 20-29 recorded most of the isolates $(10 / 32)$, closely followed by age group $\leq$ 9 years $(8 / 32)$.

\begin{tabular}{|c|c|c|c|c|c|}
\hline $\begin{array}{c}\text { Age*Group } \\
\text { (Years) }\end{array}$ & $\begin{array}{c}\text { Total Number of } \\
\text { Participants }\end{array}$ & $\begin{array}{c}\text { Nil Typhoidal } \\
\text { Salmonella }\end{array}$ & $\begin{array}{c}\text { S. paratyphi A } \\
\text { Isolated }\end{array}$ & $\begin{array}{c}\text { S. typhi } \\
\text { Isolated }\end{array}$ & $\begin{array}{c}\text { Total Number of } \\
\text { Isolates }\end{array}$ \\
\hline$\leq 9$ & 44 & 36 & 2 & 6 & 8 \\
\hline $10-19$ & 46 & 41 & 1 & 4 & 5 \\
\hline $20-29$ & 97 & 87 & 2 & 8 & 10 \\
\hline $30-39$ & 66 & 33 & 0 & 4 & 4 \\
\hline $40-49$ & 35 & 6 & 1 & 1 & 2 \\
\hline $50-59$ & 9 & 3 & 0 & 2 & 3 \\
\hline$\geq 60$ & 3 & $\mathbf{2 6 8}$ & $\mathbf{7}$ & $\mathbf{2 5}$ & 0 \\
\hline Total & $\mathbf{3 0 0}$ & & & $\mathbf{3 2}$ \\
\hline
\end{tabular}

Table 2: Distribution of Typhoidal Salmonella Isolates According to Age*Group. 


\section{Open Access Journal of Microbiology \& Biotechnology}

Participants in this study represented 35 of the 36 states in Nigeria. Majority of participants (46/300) hailed from Kaduna State probably because the research was carried out in the capital city, followed by Kogi (34/300) and Benue $(30 / 300)$ States (Figure 2). Similarly, the highest number of isolates was recorded by Kaduna (5/32) and Benue (5/32) followed by Kogi (4/32). Sixty-two (62) spoken languages or tribes were represented, with Hausa (36/300), Yoruba $(33 / 300)$ and Ibo (25/300) topping the list and yielding 3,5 and 2 isolates respectively. Other tribes of significance were Fulani (14/300), Idoma (14/300), Igala (13/300), Tiv $(12 / 300)$, Bajju (10/300) and Kabba (10/300) yielding 1, $3,1,1,2$ and 2 isolate/s respectively. The other 53 tribes $(133 / 300)$ resulted in the remaining 12 isolates.

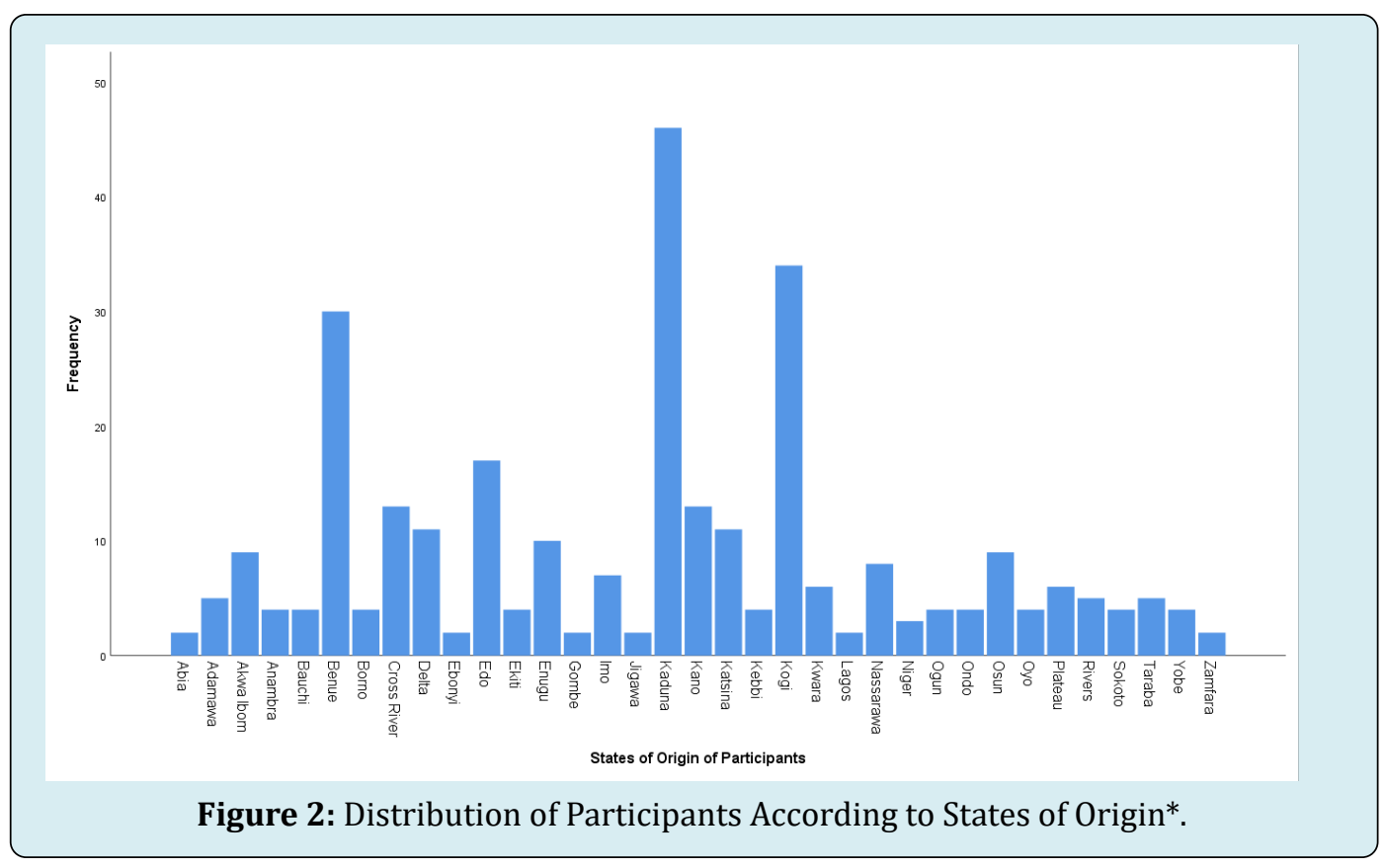

Table 3 shows the socio demographic information of the participants and distribution of typhoidal Salmonella. Females (17/32), singles (22/32) and unemployed participants (20/32) recorded more typhoidal Salmonella isolates.

\begin{tabular}{|c|c|c|c|c|c|c|}
\hline \multicolumn{2}{|c|}{ Socio Demographic Information } & $\begin{array}{c}\text { Total Number of } \\
\text { Participants }\end{array}$ & $\begin{array}{l}\text { Nil Typhoidal } \\
\text { Salmonella }\end{array}$ & $\begin{array}{l}\text { S. paratyphi } \\
\text { A Isolated }\end{array}$ & $\begin{array}{l}\text { S. typhi } \\
\text { Isolated }\end{array}$ & $\begin{array}{c}\text { Total Number } \\
\text { of Isolates }\end{array}$ \\
\hline \multirow{2}{*}{ Gender } & Male & 163 & 148 & 3 & 12 & 15 \\
\hline & Female & 137 & 120 & 4 & 13 & 17 \\
\hline \multirow{4}{*}{ Marital Status* } & Single & 194 & 172 & 5 & 17 & 22 \\
\hline & Married & 98 & 90 & 1 & 7 & 8 \\
\hline & Divorced & 3 & 2 & 1 & 0 & 1 \\
\hline & Widowed & 5 & 4 & 0 & 1 & 1 \\
\hline \multirow{4}{*}{ Employment Status } & Unemployed & 162 & 142 & 4 & 16 & 20 \\
\hline & Self Employed & 69 & 62 & 2 & 5 & 7 \\
\hline & Employed & 69 & 64 & 1 & 4 & 5 \\
\hline & Total & 300 & 268 & 7 & 25 & 32 \\
\hline
\end{tabular}

Table 3: Typhoidal Salmonella Isolated According to Socio Demographic Data.

Table 4 shows the frequency distribution of typhoidal Salmonella isolates according to the clinical information of the participants. 


\section{Open Access Journal of Microbiology \& Biotechnology}

\begin{tabular}{|c|c|c|c|c|c|c|}
\hline $\begin{array}{l}\text { Other Relevant } \\
\text { Information }\end{array}$ & Categories & $\begin{array}{c}\text { Total Number } \\
\text { of Participants }\end{array}$ & $\begin{array}{c}\text { Nil Typhoidal } \\
\text { Salmonella }\end{array}$ & $\begin{array}{l}\text { S. paratyphi } \\
\text { A Isolated }\end{array}$ & $\begin{array}{l}\text { S. typhi } \\
\text { Isolated }\end{array}$ & $\begin{array}{c}\text { Total Number } \\
\text { of Isolates }\end{array}$ \\
\hline \multirow{7}{*}{$\begin{array}{l}\text { Frequency of } \\
\text { Infection* }\end{array}$} & Monthly & 1 & - & - & 1 & 1 \\
\hline & Quarterly & 36 & 27 & 2 & 7 & 9 \\
\hline & Twice a year & 89 & 80 & 3 & 6 & 9 \\
\hline & Once a year & 129 & 120 & 2 & 7 & 9 \\
\hline & Once in many years & 1 & 1 & - & - & - \\
\hline & First time & 4 & - & - & 4 & 4 \\
\hline & Never & 40 & 40 & - & - & - \\
\hline \multirow{6}{*}{ Type of treatment } & $\begin{array}{l}\text { Hospital based } \\
\text { treatment }\end{array}$ & 173 & 153 & 2 & 18 & 20 \\
\hline & Self-Medication & 25 & 22 & 1 & 2 & 3 \\
\hline & $\begin{array}{c}\text { Chemist } \\
\text { Prescription } \\
\end{array}$ & 32 & 28 & 3 & 1 & 4 \\
\hline & Herbal treatment & 27 & 25 & 1 & 1 & 2 \\
\hline & Not applicable & 43 & 40 & - & 3 & 3 \\
\hline & Total & 300 & 268 & 7 & 25 & 32 \\
\hline
\end{tabular}

Table 4: Typhoidal Salmonella Isolated According to Clinical Information Obtained from Participants.

The CLSI 2017 guidelines was the standard for interpreting diameters of zone of inhibitions of antibiotics tested and the result is summarized on Table 5.

\begin{tabular}{|c|c|c|c|c|c|c|c|c|c|c|c|c|c|c|c|c|c|c|c|c|c|c|c|c|}
\hline \multirow[t]{2}{*}{ Antibiotics } & \multicolumn{3}{|c|}{ CPR } & \multicolumn{3}{|c|}{ NIT } & \multicolumn{3}{|c|}{ OFL } & \multicolumn{3}{|c|}{ GEN } & \multicolumn{3}{|c|}{ CXM } & \multicolumn{3}{|c|}{ CRX } & \multicolumn{3}{|c|}{ CAZ } & \multicolumn{3}{|c|}{ AUG } \\
\hline & $S$ & I & $\mathrm{R}$ & $S$ & I & $\mathrm{R}$ & $S$ & I & $\mathrm{R}$ & $S$ & I & $\mathrm{R}$ & $S$ & I & $\mathrm{R}$ & $S$ & I & $\mathrm{R}$ & $S$ & I & $\mathrm{R}$ & $S$ & I & $\mathrm{R}$ \\
\hline S. paratyphi A & 5 & 2 & - & 3 & 2 & 2 & 6 & - & 1 & 4 & 1 & 2 & - & 1 & 6 & - & 1 & 6 & - & 1 & 6 & - & - & 7 \\
\hline S. typhi & 16 & 5 & 4 & 19 & 4 & 2 & 18 & 2 & 5 & 14 & - & 11 & 1 & 3 & 21 & - & 4 & 21 & - & 3 & 22 & - & - & 25 \\
\hline Total & 21 & 7 & 4 & 22 & 6 & 4 & 24 & 2 & 6 & 18 & 1 & 13 & 1 & 4 & 27 & - & 5 & 27 & - & 4 & 28 & - & - & 32 \\
\hline $\begin{array}{l}\text { Percentage } \\
\text { Resistance }\end{array}$ & 12.5 & & & 12.5 & & & 18.8 & & & 40.6 & & & 84.4 & & & 84.4 & & & 87.5 & & & 100 & & \\
\hline
\end{tabular}

Table 5: Summary of Antibiotic Susceptibility Test of Typhoidal Salmonella Isolated.

Ciprofloxacin (CPR) Nitrofurantoin (NIT) Ofloxacin (OFL) Gentamicin (GEN) Cefixime (CXM) Cefuroxime (CRX) Ceftazidime (CAZ) Augmentin (AUG) Susceptible to antibiotic (S) Intermediate level susceptibility to antibiotic (I) Resistant to antibiotic (R). All 32 isolates were resistant to Augmentin, a combination of amoxicillin and clavulanic acid (100\% resistance). Twenty-eight (28) isolates (22 S. typhi and six S. paratyphi A) were resistant to Ceftazidime $(87.5 \%$ resistance), 27 isolates (21 S. typhi and six S. paratyphi A) were resistant to both Cefuroxime and Cefixime (84.4\% resistance), 13 isolates ( $11 \mathrm{~S}$. typhi and two S. paratyphi A) were resistant to Gentamicin (40.6\% resistance), six (6) isolates (five $S$. typhi and one S. paratyphi A) were resistant to Ofloxacin (18.8\% resistance) and four (4) isolates were resistant to both Nitrofurantoin and Ciprofloxacin $(12.5 \%$ resistance). Interestingly, the four isolates resistant to
Ciprofloxacin were $S$. typhi isolates only, as compared to Nitrofurantoin having two $S$. typhi and two S. paratyphi A isolates resistant to it (Table 5).

A summary of the order of presenting signs and symptoms documented by participants were; Headache $(137 / 300)>$ Weakness of the body $(110 / 300)>$ High temperature $(105 / 300)>$ Vomiting $(77 / 300)>$ Abdominal pain $(73 / 300)>$ Fever $(71 / 300)>$ Body pain $(55 / 300)>$ Cold $(51 / 300)>$ Dizziness $(11 / 300)>$ Joint pain $(7 / 300)$ $>$ Loss of appetite $(5 / 300)>$ Cough $(4 / 300)>$ Pus on the mouth $(3 / 300)>$ Rashes $(2 / 300)>$ Drowsiness $(1 / 300)$, Pains (1/300), Chest pain (1/300) and Diarrhoea (1/300). The number of typhoidal Salmonella isolated during the study duration is shown on Figure 3. 


\section{Open Access Journal of Microbiology \& Biotechnology}

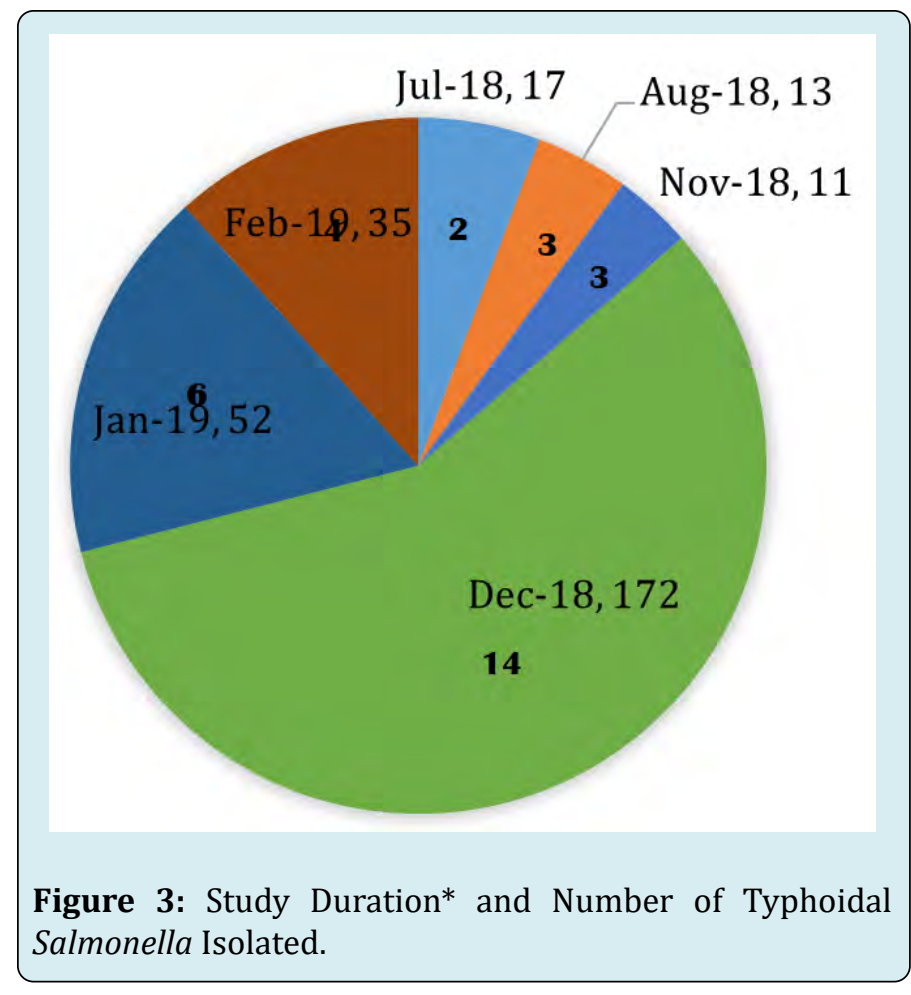

\section{Discussion}

Antimicrobial resistance of typhoidal Salmonella isolates to first-generation quinolones and antimicrobial agents like nalidixic acid, amoxicillin, ampicillin, chloramphenicol and trimethoprim-sulfamethoxazole; and even third-generation cephalosporins like ceftriazone, have been reported by previous studies $[9,16,17]$, therefore, a set of gram negative antibiotics expected to be effective against typhoidal Salmonella isolates was investigated in this study. A strong relationship existed between antibiotic resistance and the typhoidal Salmonella isolates in this study $(\mathrm{p}=0.000)$. High antibiotic resistance was observed especially with Augmentin showing 100\% resistance, Ceftazidime showing 87.5\% resistance, Cefuroxime and Cefixime showing $84.4 \%$ resistance and Gentamicin showing $40.6 \%$ resistance. Ofloxacin showing $18.8 \%$ resistance, Nitrofurantoin and Ciprofloxacin both showing $12.5 \%$ resistance, did not show very high resistance. Nevertheless, multi-drug resistance was established in this study. Ciprofloxacin was found to be the most effective antibiotic tested, as it was effective against all isolates of $S$. paratyphi A while four $S$. typhi isolates showed resistance. This was followed by Nitrofurantoin which had two $S$. paratyphi A and two $S$. typhi isolates resistant to it (Table 5). Augmentin was the least effective antibiotic tested as all 32 isolates were resistant to it.

It was observed in this study that individuals may show high antibiotic resistance to typhoidal Salmonella infections as a result of high exposure to the infection and the continual use of antibiotics, as a total of 27 isolates where recovered from participants who claimed to be infected either quarterly (9), twice a year (9) or at least once every year (9) (Table 4). This was revealed in an association between antibiotic resistance and frequency of infection ( $p=0.001)$ in this study. Similarly, the presenting symptoms recorded in this study had a strong relationship with antibiotic resistance $(p=0.001)$ and the summarized order of presenting signs and symptoms in this study shared similarities with the reports of previous studies $[16,20]$. Clinical manifestations of typhoid infections are similar to common febrile ailments like malaria and dengue fever [17], therefore, careful diagnostic measures by health care providers before administering antibiotic treatments should be priority, to curb the multi-drug/high antibiotic resistance of typhoidal Salmonella.

One hundred and seventy-three participants agreed to a hospital based treatment in the event of a typhoid infection and recorded 20 of the 32 isolates. Other isolates were found among those who agreed to chemist prescription (4/32), selfmedication (3/32), and herbal treatment $(2 / 32)$ (Table 4). This finding most likely suggest the high antibiotic resistance observed in the present study; which could be results of over prescription of antibiotics by health personnel, or instituted treatment without thorough confirmatory diagnosis. Hence, there is a need for proper diagnosis and management of typhoid infections. This should include providing proper health care services, properly trained laboratory and health care personnel to diagnose and manage typhoid infections respectively, provision of appropriate diagnostic laboratories and materials, and public health enlightenment on the dangers of not undergoing optimal and timely treatment of typhoid infections, as also suggested by previous studies $[18,19]$. Diagnosis should be done preferably by culturing causative Salmonella at least from stool, other than just the popular Widal test; and antibiotic susceptibility test should also be done before prescribing antibiotic treatment [20]. This will limit high antibiotic resistance and multi-drug resistance of typhoidal Salmonella [20].

There was a statistical association between antibiotic resistance and age of participants $(\mathrm{p}=0.034)$ as well as marital status $(p=0.001)$, suggesting that these sociodemographic factors contributed to the antibiotic resistance of typhoidal Salmonella observed in this study. In like manner, the close association of antibiotic resistance and states of origin $(p=0.001)$, also suggest that, there might be environmental or genetic factors common to individuals of a locality, tribe or area, that influences antibiotic resistance of typhoidal Salmonella. The study duration was also seen to be associated with antibiotic resistance ( $p=0.002)$, showing that times or seasons of the year could influence antibiotic resistance of typhoidal Salmonella. 


\section{Open Access Journal of Microbiology \& Biotechnology}

\section{Conclusion}

The strong relationship observed with typhoidal Salmonella isolates and antibiotic resistance, as well as high antibiotic resistance observed with antibiotics including Augmentin, Ceftazidime, Cefuroxime, Cefixime and Gentamicin, suggest a need for intensified efforts in the control and prevention of antibiotic resistant typhoid infection among the populace. Therefore, beyond looking at better ways to treat typhoidal Salmonella infections by overcoming their virulent characteristics with antimicrobials, public health measures such as provision of adequate healthcare and promotion of sanitary living conditions of persons residing in underdeveloped or poorly developed areas is relevant. This will reduce frequency of exposure to typhoid infection and curb the spread of high or multi-drug resistant typhoidal Salmonella.

\section{Acknowledgements}

We appreciate all participants and health facilities that contributed to this study and The Ministry of Health Kaduna State for their maximum cooperation. We also acknowledge NNPC Industrial Clinic Kaduna for their support and especially the laboratory for their assistance.

\section{References}

1. Casadesus J (2011) Salmonella: From basic science to clinical issues. Future Microbiol 6(2): 133-135.

2. Dougan G, Baker S (2014) Salmonella enteric serovar Typhi and the pathogenesis of typhoid fever. Annu RevMicrobiol 68: 317-336.

3. Winter SE, Winter MG, Godinez I, Yang HJ, Russmann H, et al. (2010) A rapid change in virulence gene expression during the transition from the intestinal lumen into tissue promotes systemic dissemination of Salmonella. PLoS Pathog 6(8): e1001060.

4. Appiah GD, Hughes MJ, Stephens KC (2018) Travel related infectious diseases - Typhoid and paratyphoid fever. CDC Travelers' health.

5. WHO (2020) World Health Organization, Geneva, Switzerland.

6. Bharmoria A, Vaish VB, Tahlan AK, Majumder S (2016) Analysis of attributing characteristics of Salmonella enterica serovar Paratyphi A, B and C across India, during 6 years (2010 to 2015). J Med Microbiol \& Diagn 5(1): 1000220.

7. Tauxe R, Medalla F, Wise M, Folster J (2014) Salmonella, the persistent pathogen. APUA Newsletter 32(3): 12-13.
8. Fabiani FD, Renault TT, Peters B, Dietsche T, Galvez EJC, et al. (2017) A flagellum-specific chaperone facilitates assembly of the core type III export apparatus of the bacterial flagellum. PLOS Biol 15(8): e2002267.

9. Brooks GF, Caroll KC, Jawetz E, Melnick JL, Adelberg EA, et al. (2013) Jawetz, Melnick and Adelberg's Medical Microbiology, $26^{\text {th }}$ (Edn.), McGrawHill Publishers, New York, USA, pp: 864.

10. Buckle GC, Fischer Walker CL, Black RE (2012) Typhoid fever and paratyphoid fever: Systematic review to estimate global morbidity and mortality for 2010. J Glob Health 2(1): 1010401.

11. Crump JA, Mintz ED (2010) Global trends in typhoid and paratyphoid fever. Clin Infect Dis 50(2): 241-246.

12. Onwumere M, Dogara MD, Aboh H, Gyuk P, Akutson S, et al. (2017) An economic analysis on the viability of harnessing wind energy for power generation in Kaduna State, Nigeria. Sci J Energy Eng 5(5): 124-129.

13. (2020) Paramedics World.

14. (2020) Learn Microbiology Online. Medical Microbiology Guide.

15. (2017) M100 Performance standards for antimicrobial susceptibility testing, $27^{\text {th }}$ (Edn.), Clinical and Laboratory Standards Institute, Wayne, USA, pp: 282.

16. CDC (2019) Atlanta. Centre for Disease Control and Prevention.

17. Wijedoru L, Mallett S, Parry CM (2017) Rapid diagnostic tests for typhoid and paratyphoid (enteric) fever. Cochrane Database of Syst Rev 5(5): CD008892.

18. Ochiai RL, Acosta CJ, Danovaro-Holliday MC, Baiqing D, Bhattacharya SK, et al. (2008) A study of typhoid fever in five Asian countries: Disease burden and implications for controls. Bull World Health Organ 86(4): 260-268.

19. Birhanie M, Tessema B, Ferede G, Endris M, Enawgaw B, et al. (2014) Malaria, typhoid fever and their coinfection among febrile patients at a rural health centre in Northwest Ethopia: A cross sectional study. Adv Med 2014: 531074 .

20. Nsutebu EF, Martins P, Adiogo D (2003) Prevalence of typhoid fever in febrile patients with symptoms clinically compatible with typhoid fever in Cameroon. Trop Med Int Health 8(6): 575-578. 